\title{
Considering the Prospect of Utilizing Anaerobic Membrane Biofouling Layers Advantageously for the Removal of Emerging Contaminants
}

\author{
Christelle BouNehme Sawaya and Moustapha Harb* \\ Department of Civil and Environmental Engineering, Lebanese American University, Byblos, Lebanon
}

\section{OPEN ACCESS}

Edited by:

Luca Fortunato,

King Abdullah University of Science and Technology, Saudi Arabia

Reviewed by:

Chun-Hai Wei,

Guangzhou University, China

Nadia Farhat,

King Abdullah University of Science

and Technology, Saudi Arabia

Claudia Lorena Sanchez-Huerta, Water Desalination and Reuse Center,

King Abdullah University of Science and Technology Thuwal, Saudi Arabia,

in collaboration with reviewer NF

${ }^{*}$ Correspondence:

Moustapha Harb

moustapha.harb@lau.edu.lb

Specialty section: This article was submitted to

Separation Processes,

a section of the journal

Frontiers in Chemical Engineering

Received: 15 December 2020 Accepted: 18 January 2021

Published: 15 February 2021

Citation:

BouNehme Sawaya $C$ and Harb $M$ (2021) Considering the Prospect of

Utilizing Anaerobic Membrane Biofouling Layers Advantageously for the Removal of

Emerging Contaminants.

Front. Chem. Eng. 3:642280.

doi: 10.3389/fceng.2021.642280
Membrane biofilm formation has traditionally been perceived as a wholly negative occurrence in membrane filtration-based wastewater treatment systems due to its resultant effect on transmembrane pressure and energy expenditure. This is the case for both membrane bioreactor (MBR) systems, generally, and anaerobic membrane bioreactors (AnMBRs), specifically. Insight gained through recent research, however, has revealed a potentially positive aspect to biofouling in AnMBR systems-namely, the improved removal of certain emerging contaminants (both microbial and chemical) from wastewater that would not otherwise be retained by the microfiltration/ultrafiltration membranes that are commonly used. Although the exact reasons behind this are not yet understood, the biofilm-specific anaerobic microbial communities that develop on membrane surfaces may play a key role in the phenomenon. Mechanisms of biofouling development in AnMBRs have recently been proven distinctly different from those that govern fouling in aerobic MBR systems. Based on these differences, it may be possible to devise operational strategies that promote the development of anaerobic biofilms on membranes while also minimizing transmembrane pressure increases. If achievable, this would serve as a sustainable basis for reducing the release of emerging contaminants such as organic micropollutants (OMPs) and antibiotic resistance genes (ARGs) with treated wastewater effluents.

Keywords: antibiotic resistance genes (ARGs), organic micropollutant, membrane, fouling, AnMBR (anaerobic membrane bioreactor), biofilm, bioreactor, microbial

\section{INTRODUCTION}

The concept of what constitutes an emerging contaminant is, by nature, continuously evolving. In wastewater treatment, organic micropollutants (OMPs) such as pharmaceuticals, pesticides, personal care products, and endocrine disrupting compounds continue to be of great concern globally (Barbosa et al., 2016; Ben et al., 2018). However, when defining emerging contaminants, the threat of antibiotic resistance must not be overlooked. Antibiotic resistance genes (ARGs) have also long been considered emerging contaminants due to their ever-increasing potential to spread resistance to pathogenic bacteria (Pruden et al., 2006).

When considering adapting wastewater treatment plant design for the purpose of reducing the spread of such emerging contaminants, the sustainability of the processes involved is also an eminent priority. Membrane bioreactors (MBRs), for example, have been shown to possess certain advantages 
for reducing ARG proliferation (Munir et al., 2011), while showing no real differences compared to conventional wastewater treatment with respect to overall OMP removal (Grandclément et al., 2017). Energy expenditure, however, remains a significant drawback for MBR system sustainability, with limited options for reducing energy use due to their inherent requirement of continuous aeration (Sun et al., 2016). A developing technology that also utilizes membrane separation but has high potential for energy sustainability is the anaerobic membrane bioreactor (AnMBR) (Smith et al., 2014). AnMBRs combine anaerobic biological treatment with membrane separation, thus eliminating the requirement of sludge aeration while also introducing the possibility of energy recovery in the form of methane.

Only a limited amount of research has been performed thus far on the fate of emerging contaminants in AnMBR systems. However, recent work has shown that they may possess certain distinguishing advantages for the reduction of both OMPs and ARGs in wastewater effluents. Although removal of OMPs in wastewater treatment (generally) is partly dependent on pollutant-specific characteristics, anaerobic biofilm-based retention and degradation would likely provide combined positives for improving removal rates overall (Harb et al., 2019). Likewise, membrane separation and anaerobic digestion are also known to be jointly beneficial to the reduction of ARGs in wastewater effluents (Harb and Hong, 2017).

The membrane biofouling layer in MBR systems (both aerobic and anaerobic) has also been shown to elicit benefits for emerging contaminant rejection and removal. Still, these benefits are overshadowed by the increased energy demands associated with biofouling and its control processes. Recent research, however, has elucidated explicit and fundamental differences between the fouling mechanisms governing AnMBR and aerobic MBR membrane system blockage (Yao et al., 2020b). A majority of prior research on AnMBR biofouling characteristics had assumed certain similarities to conventional (aerobic) MBR systems and, as such, potentially inhibited the exploration of novel bases for membrane fouling control. In the following, we examine the potential advantageous aspects of anaerobic membrane biofouling in AnMBRs for removal of emerging contaminants. We also explore the implications of newly characterized AnMBR biofouling mechanisms on the possibility of sustaining low-pressure anaerobic biofilms in such systems.

\section{THE POSITIVE EFFECTS OF BIOFOULING IN AnMBRs ON OMP REMOVAL}

OMPs are known to have wide-ranging impacts (in terms of toxicity and mutagenicity) on receiving water environments (Shao et al., 2019). Their removal in wastewater treatment systems is complicated by the recalcitrance caused by compound-specific properties (Grandclément et al., 2017). With membrane-combined treatment systems (i.e., MBRs) becoming increasingly common worldwide, their utility for improved OMP removal should be thoroughly considered.
The effects of membrane fouling on OMP retention in MBRs has generally been found as positively correlated (Sanguanpak et al., 2019). As should be expected, OMP compound type plays a key role in the level of retention achievable within membrane biofilms. Specifically, hydrophobic OMPs have been found as highly maintained in fouling layers due to their increased affinity for fouling layer constituents such as extracellular polymeric substances (EPS). Although this is the case for both AnMBRs and aerobic MBRs, compound biodegradability within the fouling layer ultimately dictates how effective the initial retention in biomass due to hydrophobicity can be on ultimate removal rates. This is particularly relevant to the different microbial groups that occupy aerobic vs. anaerobic membrane biofilms. Alternatively to hydrophobic means of increased OMP removal by membrane biofouling, actual pore blockage by EPS and soluble microbial products (SMP) can further help in the rejection of OMPs that would otherwise permeate membrane pores (Cheng et al., 2018). This is applicable to both hydrophobic and hydrophilic compounds alike. However, reliance on such means of compound rejection is not preferable, as they would concurrently result in increased transmembrane pressure.

One of the only studies thoroughly investigating OMP retention by AnMBR membrane biofilms found that, similar to in aerobic systems, a majority of OMPs with high removal contribution by the fouling layer were hydrophobic (Monsalvo et al., 2014). Those compounds included 17a-estradiol, 17aethynylestradiol, amitriptyline, bisphenol A, clozapine, estrone, linuron, octylphenol, and triclosan, whose biofilm-based retention ranged between 10 and $80 \mathrm{mg} / \mathrm{m}^{2}$ of membrane surface area. Incidentally, all of these compounds were found in a different study to be highly biodegradable by anaerobic biomass (Wijekoon et al., 2015), implying that the retention of such compounds in the membrane fouling layer did, in fact, aid in their overall removal.

\section{MEMBRANE BIOFILM MICROBIAL COMMUNITIES IN AnMBRs}

Due to the inherent differences of the biological processes used in AnMBRs as compared to aerobic MBRs, it is to be expected that the microbiomes of the membrane biofouling layers of each system type will have essentially no overlap. In the case of the more widespread aerobic MBR, extensive work has been done on analyzing aerobic biofouling layer microbial communities in fullscale systems (Choi et al., 2017; Matar et al., 2017; Wang et al., 2020). Despite no full-scale AnMBR systems' membrane biofilm having been similarly analyzed so far, the lab- and pilot-scale studies that performed such characterization have provided insights into microorganisms that are commonly present.

A recently-published review on the main microbiota of AnMBRs has indicated that the microbial communities of membrane biofouling layers are dominated by a combination of fermentative, syntrophic, and methanogenic microbes (Cheng et al., 2019). Additionally, between the 12 analyzed AnMBRs, a core group of microorganisms was found to be present in all systems' membrane biofilm samples. This group included the 


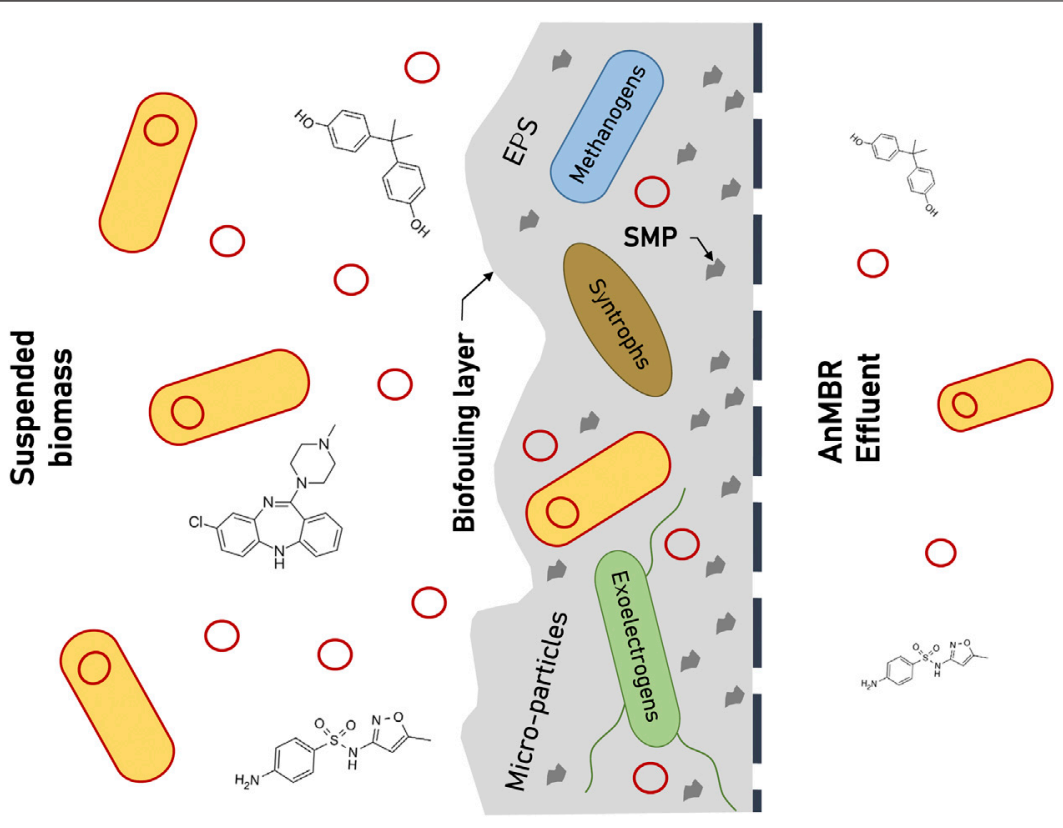

FIGURE 1 | Schematic representation of membrane biofilm components and communities that contribute to the enhanced removal of organic micropollutants (OMPs) and antibiotic resistance genes (ARGs) in anaerobic membrane bioreactor (AnMBR) systems. Red circles indicate extracellular antibiotic resistance elements and yellow cells represent ARG-carrying bacteria.

genera: Acinetobacter, Geobacter, Lactococcus, Smithella, Syntrophomonas, Syntrophorhabdus, Methanothrix, Methanospirillum, and Methanobacterium. Among these, the syntrophic and methanogenic genera, specifically, showed consistently high relative abundances across several of the reactors' membrane biofilms. Although significant, this is not surprising considering that anaerobic biofilms (as compared to suspended biomass) have the potential to increase syntrophic cooccurrence of these two groups (Harb et al., 2015). The presence of Geobacter as a core bacterium in AnMBR biofilms has additional implication, considering that several species of this genus are known to be exoelectrogenic (Rotaru et al., 2015). Another more recent study on AnMBR biofouling showed that other potentially-exoelectrogenic bacteria (certain sulfatereducing groups) could also be enriched in biofilms under various conditions (Zhou et al., 2019). In addition, it was recently discovered that certain Methanospirillum species are considered electrically conductive (Walker et al., 2019). These observations imply that, in addition to syntrophic-methanogenic interaction, exoelectrogenic activity may also play an essential role in AnMBR membrane biofilm activity (Figure 1).

It is important to note that the core microbial groups of membrane biofilms in AnMBRs have also been observed to be dominant in other AnMBR system biofilm components (whenever such components have been incorporated as part of reactor design). For example, in a staged anaerobic fluidized bed membrane bioreactor (SAF-MBR), granular activated carbon particles were shown to carry biofilms dominated by Geobacter, Smithella, and Methanothrix (Aslam et al., 2018). Likewise, an anaerobic filter-type AnMBR (utilizing ceramic biofilm carriers) was also found to have a high level of microbial similarity between in-reactor biofilm carriers and the membrane biofilms themselves (Harb et al., 2015). Although the conditions under which biofilms develop on reactor carriers $v s$. on membranes are markedly different (i.e., due to shear forces from cross flow and/or biogas sparging on the latter), ultimate microbial community structure appears to promote analogous syntrophic and methanogenic activity.

\section{BIODEGRADABILITY OF OMPS BY KEY ANAEROBIC MICROBIAL GROUPS}

Mainstream anaerobic wastewater treatment (generally) is inherently required to rely more heavily on biodegradation of OMPs than is aerobic wastewater treatment at steady-state operation. This is due to the relatively negligible level of sludge wasting employed in anaerobic treatment systems, which results in only a miniscule fraction of any sludgeadsorbed compounds exiting the system (Harb et al., 2019). This is no less true in the case of AnMBRs, as they are capable of being operated at nearly infinite solids retention times (SRTs). Thus, when discussing the concept of "overall removal" of OMPs from AnMBRs, understanding the processes of OMP biodegradation is of utmost importance. Further to this, anaerobic biofilm communities (generally) have been documented as possessing distinct differences compared to those that occur in suspended anaerobic sludge (e.g., in continuously stirred reactors), with syntrophic and methanogenic consortia being more prevalent within biofilms (Harb et al., 2015). When combined with the intrinsic compound retention capacity of biofilms, the potential for effective anaerobic 
degradation of OMPs by these biofilm communities can be significantly improved (Harb et al., 2019).

Based on the above-described notions, it is reasonable to also consider the prospect of enhanced OMP removal through biodegradation by anaerobic membrane biofilm microbial communities. Using the core microbial groups described in the previous section as a starting point, one concept that stands out is the recently-elucidated essential role that methanogens play in OMP degradation. Methanogenesis and its associated enzymes (e.g., acetate kinase) have been shown to account for large fractions of OMP biotransformation in the anaerobic process (Gonzalez-Gil et al., 2017; Gonzalez-Gil et al., 2018). Other digestion steps (such as acidogenesis) have also been shown to contribute to OMP removal. For instance, significant correlations with antibiotic removal have been observed for co-occurring microbial communities of hydrogenotrophic methanogens (Methanomicrobiales) and homoacetogens (Cetecioglu et al., 2016). Similar results were also reported for methanogens in association with syntrophic groups that include Syntrophobacter and Syntrophorhabdus for the degradation of antibiotics in anaerobic fixed-bed biofilm reactors (Carneiro et al., 2020b). Thus, the co-metabolic nature of methanogenesis in conjunction with syntrophic and/or acidogenic bacteria appears to be highly advantageous to degradation of a significant fraction of OMPs (Carneiro et al., 2020a). This has far-reaching implications for the prospect of maintaining a lowlevel fouling membrane biofilm in AnMBRs that contains such consortia. Further to this, the concurrent presence of exoelectrogens in AnMBR biofilms (such as certain Geobacter and Desulfovibrio species) are also likely to aid in the degradation of multiple antibiotic-type OMPs, as has been recently reported (Chang et al., 2019; Chen et al., 2020).

\section{BIOFOULING AND ARG REMOVAL: THE IMPORTANCE OF INTRACELLULAR AND EXTRACELLULAR ARG DIFFERENTIATION}

The dynamic nature of antibiotic resistance transmission causes ARGs to proliferate through multiple avenues (e.g., in plasmids, chromosomes, transposons, etc.). This allows ARGs to occur both intracellularly and extracellularly, thus causing a logistical challenge when targeting their removal. Nonetheless, recent advances in understanding the state of existence and transfer of ARGs in water and wastewater environments could soon pave the way for their effective management and mitigation (ZareiBaygi and Smith, 2020).

Preliminary investigations into the removal of ARGs by membrane filtration have indicated that, for the types of membranes used in AnMBRs, removal rates of plasmid-based ARGs ranged between 1 and $2 \log$ (Breazeal et al., 2013). Naturally, ARGs present in bacterial cells (either as plasmid DNA or chromosomal DNA) would inevitably be even more efficiently removed by similar non-fouled membranes. Thus, the effective differentiation between intracellular DNA (within bacterial cells) and extracellular DNA (outside of bacterial cells) can play a key role in determining the mechanisms through which ARGs are removed by operational membranebased wastewater treatment systems.

With respect to AnMBRs, specifically, only two studies to date have attempted to characterize the effects of intracellular $v s$. extracellular ARG presence on membrane biofouling-based removal. Interestingly, both of these works came to similar conclusions regarding the effects of membrane biofouling development. One of these was a targeted study by Cheng and Hong that was aimed at assessing the removal of ARGs by utilizing anaerobically-fouled polyvinylidene fluoride (PVDF) microfiltration membranes (ex-situ) (Cheng and Hong, 2017). Results of this work indicated that several tested antibiotic resistant bacteria (ARB) were most effectively removed by low-fouled membranes. Inversely, the corresponding ARGcontaining plasmids of these ARB, when tested extracellularly, actually increased in removal when biofouling rates were intensified. Other recent work by Zarei-Baygi et al. also aimed to differentiate the effects of anaerobic biofouling rates on ARG removal, in this case, in an operational AnMBR system (ZareiBaygi et al., 2020). This study also found that intracellular ARGs (those present in ARB) were more effectively removed at low fouling rates, whereas extracellular ARGs (those commonly contained on plasmids) were better removed during highlyfouled conditions. These results indicate a likely positive effect of EPS and SMP accumulation in the fouling layer on improved rejection of extracellular ARGs, while the increased transmembrane pressure caused by these foulants may cause more suspended sludge-based and/or biofilm-associated ARB to break through the actual membrane barrier. It has been postulated that the higher abundances of intracellular ARGs present in effluents during elevated transmembrane pressure operation could be due to the deformability of bacterial cells causing their passage through membrane pores (Zarei-Baygi et al., 2020). This explanation seems plausible, especially considering the size range of microfiltration membrane pores and the nature of absolute vs. nominal pore size distribution (Suchecka et al., 2005).

\section{DISTINCTIVE BIOFOULING MECHANISMS ARE ASSOCIATED WITH AnMBRS}

One of the outstanding challenges facing the adoption of AnMBRs for the purpose of full-scale domestic wastewater treatment is the reality that consistently effective membrane fouling mitigation strategies have yet to be established. This is partly due to the fact that AnMBR foulant characterization (and system operational strategy development based on this characterization) is still in its relatively early stages. An interesting aspect to AnMBR membrane unit operation, however, is that membranes have been reportedly operable for extended periods of time with only minimal increases in transmembrane pressure (Robles et al., 2012; Gouveia et al., 2015). Further, AnMBR membrane biofilms have recently been described to contain consistent EPS and biomass content (per membrane surface area) both before and after transmembrane pressure jumps (Yao et al., 2020a). This stands 
in stark contrast to the conventional understanding of membrane fouling mechanisms as they relate to aerobic MBRs.

A Number of studies have aimed at determining specific differences between AnMBR and aerobic MBR foulant characteristics and their effects on membrane pore blockage. An early work on the topic had reported that particle sizes in an approximate range of $1-2 \mu \mathrm{m}$ were uniquely found in AnMBR systems after long-term operation, while also reporting that protein to carbohydrate ratios in the SMP were markedly higher than in a concurrently operated aerobic MBR (Martin-Garcia et al., 2011). Other work comparing AnMBRs with aerobic MBRs has also implicated the potential importance of the SMP protein fraction in biofouling. Specifically, Xiong et al. found that a $640 \mathrm{kDa}$ protein SMP compound directly correlated with the level of membrane fouling, despite such a compound size having been significantly smaller than the $0.3 \mu \mathrm{m}$ pore size of the membranes employed (Xiong et al., 2016). These studies indicated the potential importance of the proteinaceous fraction of SMPs in fouling, while also suggesting that compounds and particles in reactor suspension likely play a more important role in AnMBR fouling than they do in aerobic MBR systems.

Perhaps most notably, various recent investigations of AnMBR foulants have shed light on the role of micro-particles and how they can directly affect fouling rates as compared to aerobic MBRs. A 2016 study by Zhou et al. reiterated previous findings that particles and colloids in the range of $0.45-10 \mu \mathrm{m}$ played an integral part in AnMBR fouling, as did their associated microbial compositions (Zhou et al., 2016). When Zhou and coworkers performed a subsequent study characterizing the breakdown of micro-particles within this range $(0.45-10 \mu \mathrm{m})$, they found that colloidal particles of sizes $0.45-1 \mu \mathrm{m}$ were the specific fraction that resulted in severe pore blockage (Zhou et al., 2019). The neglected nature of micro-particles in AnMBRs was, most recently, directly compared to their possible role in aerobic MBR systems (Yao et al., 2020b). Results of this study were highly indicative that micro-particles play little to no role in fouling of aerobic MBRs, whose membrane fouling layers are dominated by EPS from the bulk sludge. AnMBR fouling layer organics were comprised of $69 \%$ micro-particles, whereas aerobic MBR fouling layer organics contained only $1.9 \%$. All of the above works highlight one commonality: that AnMBR fouling mechanisms are dominated by factors which generally do not affect aerobic MBR systems and, thus, cannot be controlled using the same fouling mitigation strategies. Based on recent discoveries, it remains likely that new strategies can be devised to promote a microbial, EPS, SMP, and micro-particle matrix that sustainably uphold low-fouling biofilm growth (Figure 1).

\section{DISCUSSION}

The AnMBR has been recognized as an emerging technology that, if operable under low fouling conditions with effluent methane recovery, can serve an integral solution for sustainable wastewater treatment and reuse moving forward (Smith et al., 2014). Although there are still operational challenges to overcome, recent developments in the understanding of membrane fouling mechanisms involved in AnMBR systems will likely lead to a breakthrough in biofouling mitigation strategies in the near future. Considering on the concepts outlined in this study's work, such mitigation strategies can be developed in conjunction with targeted approaches for the enhancement of emerging contaminant removal. The basis of removal for specific emerging contaminant subtypes can, thus, be established using the known/implied mechanisms of retention and/or biodegradation as outlined in the recent work described herein.

Specific benefits of well-controlled anaerobic membrane biofilms (in relation to specific emerging contaminant subtypes) are summarized in Figure 2. With respect to hydrophobic OMPs, the advantageous adsorption of such compounds onto membrane biofilms and their subsequent biodegradation can be promoted by the enhancement of a methanogenic, syntrophic, and exoelectrogenic microbial consortium within the membrane biomass. Hydrophilic OMPs could be concurrently controlled by the establishment of a naturally denser membrane biofilm that includes EPS from the bulk solution, as well as micro-particles in a range greater than $0.45-1 \mu \mathrm{m}$. This would promote their rejection by the membrane biofilm, as well as their resultantly improved biodegradability within the AnMBR suspended biomass.

Regarding ARGs, their overall enhanced removal will be dependent on reducing effluent concentrations of both their intracellular and extracellular components. It has become apparent from recent work that maintaining low transmembrane pressure in AnMBRs is essential to minimizing the release of intracellular ARGs/ARB. The solution to reducing extracellular ARG transmission from AnMBR effluents, however, may lie in promoting higher levels of targeted EPS, SMP, and/or micro-particle fractions that are determined to have minimal effects on actual fouling rates. To achieve this, it is therefore proposed to incorporate fouling mitigation strategies that facilitate dense membrane biofilm development that is comprised of both sludge-based carbohydrate-type EPS and a predominantly syntrohic-methanogenic consortium.

Although it was originally thought that high-density membrane biofilms would inevitably result in high transmembrane pressure, recent work has shown that the two circumstances are not necessarily correlated in AnMBR membrane biomasses (Yao et al., 2020a). Only a very specific fraction of micro-particles and SMP have been shown to affect transmembrane pressure increases in AnMBR systems. As such, it remains thoroughly possible that operational strategies can be devised to support biofilm growth on membranes that promote both the sustainability of the technology overall and the enhanced removal of a wide range of emerging microbial and chemical contaminants.

Nonetheless, targeted research efforts are still needed to elucidate the most effective low-impact membrane biofilm development strategies. Based on existing work comparing AnMBR system types, it seems likely that combining biofilm carriers within AnMBR reactor units would aid in reducing long-term fouling rates. Several studies have shown that AnMBR systems employing biofilm carriers within reactor units (specifically units that are separated from the membrane module itself) can greatly reduce fouling-relevant ranges of both SMP 


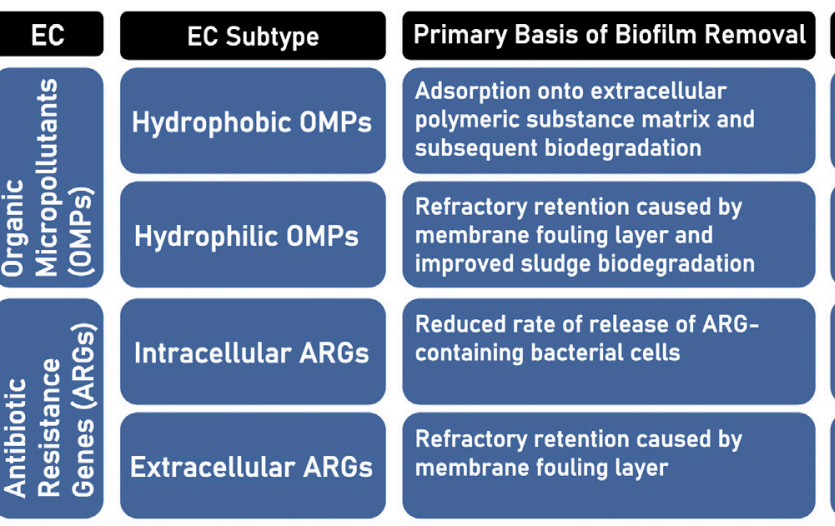

Likely Advantages of AnMBRs

Dominance of anaerobic biofilm

microbial communities by key

OMP-degrading groups

Higher biofilm density caused by

EPS, SMP, and/or Micro-particles

Lower overall ARG abundances in

anaerobic biomass compared to

aerobic biomass

Higher biofilm density caused by

EPS, SMP, or Micro-particles

FIGURE 2 | Categorization of the emerging contaminant (EC) types and subtypes addressed in this study, their primary basis for biofilm-based removal, and the possible advantages to their removal by anaerobic membrane bioreactor (AnMBR) systems.

fractions and particle fractions in the bulk solution (Garcia et al., 2013; Harb et al., 2015; Chen et al., 2017). Considering the concomitant advantages of biofilms in AnMBR systems (generally) for the retention and degradation of emerging contaminants, the possible mitigation of transmembrane pressure rises by such systems is of high relevance for future work.

\section{DATA AVAILABILITY STATEMENT}

The original contributions presented in the study are included in the article/Supplementary Material, further inquiries can be directed to the corresponding author.

\section{REFERENCES}

Aslam, M., Yang, P., Lee, P.-H., and Kim, J. (2018). Novel staged anaerobic fluidized bed ceramic membrane bioreactor: energy reduction, fouling control and microbial characterization. J. Membr. Sci. 553, 200-208. doi:10.1016/j. memsci.2018.02.038

Barbosa, M. O., Moreira, N. F., Ribeiro, A. R., Pereira, M. F., and Silva, A. M. (2016). Occurrence and removal of organic micropollutants: an overview of the watch list of EU decision 2015/495. Water Res. 94, 257-279. doi:10.1016/j. watres.2016.02.047

Ben, W., Zhu, B., Yuan, X., Zhang, Y., Yang, M., and Qiang, Z. (2018). Occurrence, removal and risk of organic micropollutants in wastewater treatment plants across China: comparison of wastewater treatment processes. Water Res. 130, 38-46. doi:10.1016/j.watres.2017.11.057

Breazeal, M. V., Novak, J. T., Vikesland, P. J., and Pruden, A. (2013). Effect of wastewater colloids on membrane removal of antibiotic resistance genes. Water Res. 47 (1), 130-140. doi:10.1016/j.watres.2012.09.044

Carneiro, R. B., Gonzalez-Gil, L., Londoño, Y. A., Zaiat, M., Carballa, M., and Lema, J. M. (2020a). Acidogenesis is a key step in the anaerobic biotransformation of organic micropollutants. J. Hazard Mater. 389, 121888. doi:10.1016/j.jhazmat.2019.121888

Carneiro, R. B., Mukaeda, C. M., Sabatini, C. A., Santos-Neto, Á. J., and Zaiat, M. (2020b). Influence of organic loading rate on ciprofloxacin and sulfamethoxazole biodegradation in anaerobic fixed bed biofilm reactors. J. Environ. Manag. 273, 111170. doi:10.1016/j.jenvman.2020.111170

Cetecioglu, Z., Ince, B., Orhon, D., and Ince, O. (2016). Anaerobic sulfamethoxazole degradation is driven by homoacetogenesis coupled with

\section{AUTHOR CONTRIBUTIONS}

$\mathrm{MH}$ and CS jointly came up with the concept and the content to be included. CS conducted the literature review and constructed the paper outline. MH and CS jointly wrote and edited the manuscript.

\section{FUNDING}

This work was partially supported by the Lebanese American University's Graduate Program Scholarship (GPS) and School of Engineering Seed Fund.

hydrogenotrophic methanogenesis. Water Res. 90, 79-89. doi:10.1016/j.watres. 2015.12.013

Chang, B.-V., Chao, W.-L., Yeh, S.-L., Kuo, D.-L., and Yang, C.-W. (2019). Biodegradation of sulfamethoxazole in milkfish (chanos chanos) pond sediments. Appl. Sci. 9 (19), 4000. doi:10.3390/app9194000

Chen, C., Guo, W., Ngo, H. H., Chang, S. W., Nguyen, D. D., Nguyen, P. D., et al. (2017). Impact of reactor configurations on the performance of a granular anaerobic membrane bioreactor for municipal wastewater treatment. Int. Biodeterior. Biodegrad. 121, 131-138. doi:10.3390/app9194000

Chen, J., Tong, T., Jiang, X., and Xie, S. (2020). Biodegradation of sulfonamides in both oxic and anoxic zones of vertical flow constructed wetland and the potential degraders. Environ. Pollut. 265, 115040. doi:10.1016/j.envpol.2020. 115040

Cheng, D., Ngo, H. H., Guo, W., Liu, Y., Chang, S. W., Nguyen, D. D., et al. (2018). Anaerobic membrane bioreactors for antibiotic wastewater treatment: performance and membrane fouling issues. Bioresour. Technol. 267, 714-724. doi:10.1016/j.biortech.2018.07.133

Cheng, H., Cheng, D., Mao, J., Lu, T., and Hong, P. Y. (2019). Identification and characterization of core sludge and biofilm microbiota in anaerobic membrane bioreactors. Environ. Int. 133, 105165. doi:10.1016/j.envint.2019.105165

Cheng, H., and Hong, P. Y. (2017). Removal of antibiotic-resistant bacteria and antibiotic resistance genes affected by varying degrees of fouling on anaerobic microfiltration membranes. Environ. Sci. Technol. 51 (21), 12200-12209. doi:10.1021/acs.est.7b03798

Choi, J., Kim, E. S., and Ahn, Y. (2017). Microbial community analysis of bulk sludge/cake layers and biofouling-causing microbial consortia in a full-scale aerobic membrane bioreactor. Bioresour. Technol. 227, 133-141. doi:10.1016/j. biortech.2016.12.056 
Garcia, I. M., Mokosch, M., Soares, A., Pidou, M., and Jefferson, B. (2013). Impact on reactor configuration on the performance of anaerobic MBRs: treatment of settled sewage in temperate climates. Water Res. 47 (14), 4853-4860. doi:10. 1016/j.watres.2013.05.008

Gonzalez-Gil, L., Carballa, M., and Lema, J. M. (2017). Cometabolic enzymatic transformation of organic micropollutants under methanogenic conditions. Environ. Sci. Technol. 51 (5), 2963-2971. doi:10.1021/acs.est.6b05549

Gonzalez-Gil, L., Mauricio-Iglesias, M., Serrano, D., Lema, J. M., and Carballa, M. (2018). Role of methanogenesis on the biotransformation of organic micropollutants during anaerobic digestion. Sci. Total Environ. 622, 459-466. doi:10.1016/j.scitotenv.2017.12.004

Gouveia, J., Plaza, F., Garralon, G., Fdz-Polanco, F., and Peña, M. (2015). Longterm operation of a pilot scale anaerobic membrane bioreactor (AnMBR) for the treatment of municipal wastewater under psychrophilic conditions. Bioresour. Technol. 185, 225-233. doi:10.1016/j.biortech.2015.03.002

Grandclément, C., Seyssiecq, I., Piram, A., Wong-Wah-Chung, P., Vanot, G., Tiliacos, N., et al. (2017). From the conventional biological wastewater treatment to hybrid processes, the evaluation of organic micropollutant removal: a review. Water Res. 111, 297-317. doi:10.1016/j.watres.2017.01.005

Harb, M., Lou, E., Smith, A. L., and Stadler, L. B. (2019). Perspectives on the fate of micropollutants in mainstream anaerobic wastewater treatment. Curr. Opin. Biotechnol. 57, 94-100. doi:10.1016/j.copbio.2019.02.022

Harb, M., and Hong, P.-Y. (2017). Anaerobic membrane bioreactor effluent reuse: a review of microbial safety concerns. Fermentatio 3 (3), 39. doi:10.3390/ fermentation3030039

Harb, M., Xiong, Y., Guest, J., Amy, G., and Hong, P.-Y. (2015). Differences in microbial communities and performance between suspended and attached growth anaerobic membrane bioreactors treating synthetic municipal wastewater. Environ. Sci. Water Res. Technol. 1 (6), 800-813. doi:10.1039/ C5EW00162E

Martin-Garcia, I., Monsalvo, V., Pidou, M., Le-Clech, P., Judd, S., McAdam, E., et al. (2011). Impact of membrane configuration on fouling in anaerobic membrane bioreactors. J. Membr. Sci. 382 (1-2), 41-49. doi:10.1016/j. memsci.2011.07.042

Matar, G. K., Bagchi, S., Zhang, K., Oerther, D. B., and Saikaly, P. E. (2017). Membrane biofilm communities in full-scale membrane bioreactors are not randomly assembled and consist of a core microbiome. Water Res. 123, 124-133. doi:10.1016/j.watres.2017.06.052

Monsalvo, V. M., McDonald, J. A., Khan, S. J., and Le-Clech, P. (2014). Removal of trace organics by anaerobic membrane bioreactors. Water Res. 49, 103-112. doi:10.1016/j.watres.2013.11.026

Munir, M., Wong, K., and Xagoraraki, I. (2011). Release of antibiotic resistant bacteria and genes in the effluent and biosolids of five wastewater utilities in Michigan. Water Res. 45 (2), 681-693. doi:10.1016/j.watres.2010.08.033

Pruden, A., Pei, R., Storteboom, H., and Carlson, K. H. (2006). Antibiotic resistance genes as emerging contaminants: studies in northern Colorado. Environ. Sci. Technol. 40 (23), 7445-7450. doi:10.1021/es0604131

Robles, A., Ruano, M., Ribes, J., and Ferrer, J. (2012). Sub-critical long-term operation of industrial scale hollow-fibre membranes in a submerged anaerobic MBR (HF-SAnMBR) system. Separ. Purif. Technol. 100, 88-96. doi:10.1016/j. seppur.2012.09.010

Rotaru, A. E., Woodard, T. L., Nevin, K. P., and Lovley, D. R. (2015). Link between capacity for current production and syntrophic growth in Geobacter species. Front. Microbiol. 6, 744. doi:10.3389/fmicb.2015.00744

Sanguanpak, S., Chiemchaisri, W., and Chiemchaisri, C. (2019). Membrane fouling and micro-pollutant removal of membrane bioreactor treating landfill leachate. Rev. Environ. Sci. Biotechnol. 18, 715-740. doi:10.1007/s11157-019-09514-Z

Shao, Y., Chen, Z., Hollert, H., Zhou, S., Deutschmann, B., and Seiler, T. B. (2019). Toxicity of 10 organic micropollutants and their mixture: implications for aquatic risk assessment. Sci. Total Environ. 666, 1273-1282. doi:10.1016/j. scitotenv.2019.02.047

Smith, A. L., Stadler, L. B., Cao, L., Love, N. G., Raskin, L., and Skerlos, S. J. (2014). Navigating wastewater energy recovery strategies: a life cycle comparison of anaerobic membrane bioreactor and conventional treatment systems with anaerobic digestion. Environ. Sci. Technol. 48 (10), 5972-5981. doi:10.1021/ es5006169

Suchecka, T., Piątkiewicz, W., and Sosnowski, T. R. (2005). Is the cell retention by MF membrane absolutely safe-a hypothetical model for cell deformation in a membrane pore. J. Membr. Sci. 250 (1-2), 135-140. doi:10.1016/j.memsci.2004. 08.035

Sun, J., Liang, P., Yan, X., Zuo, K., Xiao, K., Xia, J., et al. (2016). Reducing aeration energy consumption in a large-scale membrane bioreactor: process simulation and engineering application. Water Res. 93, 205-213. doi:10.1016/j.watres.2016. 02.026

Walker, D. J. F., Martz, E., Holmes, D. E., Zhou, Z., Nonnenmann, S. S., and Lovley, D. R. (2019). The archaellum of Methanospirillum hungatei is electrically conductive. mBio 10 (2), e00579-19. doi:10.1128/mBio.00579-19

Wang, H., Liu, Z., Luo, S., Khan, R., Dai, P., Liang, P., et al. (2020). Membrane autopsy deciphering keystone microorganisms stubborn against online $\mathrm{NaOCl}$ cleaning in a full-scale MBR. Water Res. 171, 115390. doi:10.1016/j.watres.2019. 115390

Wijekoon, K. C., McDonald, J. A., Khan, S. J., Hai, F. I., Price, W. E., and Nghiem, L. D. (2015). Development of a predictive framework to assess the removal of trace organic chemicals by anaerobic membrane bioreactor. Bioresour. Technol. 189, 391-398. doi:10.1016/j.biortech.2015.04.034

Xiong, Y., Harb, M., and Hong, P.-Y. (2016). Characterization of biofoulants illustrates different membrane fouling mechanisms for aerobic and anaerobic membrane bioreactors. Separ. Purif. Technol. 157, 192-202. doi:10.1016/j. seppur.2015.11.024

Yao, Y., Xu, R., Zhou, Z., and Meng, F. (2020a). Linking dynamics in morphology, components, and microbial communities of biocakes to fouling evolution: a comparative study of anaerobic and aerobic membrane bioreactors. Chem. Eng. J., 127483. doi:10.1016/j.cej.2020.127483

Yao, Y., Zhou, Z., Stuckey, D. C., and Meng, F. (2020b). Micro-particles-a neglected but critical cause of different membrane fouling between aerobic and anaerobic membrane bioreactors. ACS Sustain. Chem. Eng. 8 (44), 16680-16690. doi:10.1021/acssuschemeng.0c06502

Zarei-Baygi, A., and Smith, A. L. (2020). Intracellular versus extracellular antibiotic resistance genes in the environment: prevalence, horizontal transfer, and mitigation strategies. Bioresour. Technol. 319, 124181. doi:10.1016/j.biortech. 2020.124181

Zarei-Baygi, A., Wang, P., Harb, M., Stadler, L. B., and Smith, A. L. (2020). Membrane fouling inversely impacts intracellular and extracellular antibiotic resistance gene abundances in the effluent of an anaerobic membrane bioreactor. Environ. Sci. Technol. 54 (19), 12742-12751. doi:10.1021/acs.est. $0 \mathrm{c} 04787$

Zhou, Z., Tan, Y., Xiao, Y., and Stuckey, D. C. (2016). Characterization and significance of sub-visible particles and colloids in a submerged anaerobic membrane bioreactor (SAnMBR). Environ. Sci. Technol. 50 (23), 12750-12758. doi:10.1021/acs.est.6b03581

Zhou, Z., Tao, Y., Zhang, S., Xiao, Y., Meng, F., and Stuckey, D. C. (2019). Sizedependent microbial diversity of sub-visible particles in a submerged anaerobic membrane bioreactor (SAnMBR): implications for membrane fouling. Water Res. 159, 20-29. doi:10.1016/j.watres.2019.04.050

Conflict of Interest: The authors declare that the research was conducted in the absence of any commercial or financial relationships that could be construed as a potential conflict of interest.

Copyright (c) 2021 BouNehme Sawaya and Harb. This is an open-access article distributed under the terms of the Creative Commons Attribution License (CC BY). The use, distribution or reproduction in other forums is permitted, provided the original author(s) and the copyright owner(s) are credited and that the original publication in this journal is cited, in accordance with accepted academic practice. No use, distribution or reproduction is permitted which does not comply with these terms. 